\title{
Nut consumption and metabolic syndrome in US adolescents
}

\author{
Roy J Kim ${ }^{1, *}$, Lu Wang ${ }^{1}$, Sarah Worley ${ }^{1}$ and David Leonard ${ }^{2}$ \\ 'Cleveland Clinic Children's Hospital, 9500 Euclid Avenue/A120, Cleveland, OH 44195, USA: ${ }^{2}$ Children's \\ Health, 1935 Medical District, Dallas, TX, USA
}

Submitted 9 October 2017: Final revision received 26 April 2018: Accepted 9 July 2018: First published online 04 September 2018

\begin{abstract}
Objective: To determine whether nut intake is associated with the prevalence of metabolic syndrome in US adolescents.

Design: A cross-sectional analysis of data from the National Health and Nutrition Examination Survey (NHANES) years 2003-2012. Anthropometric measurements, blood tests, $24 \mathrm{~h}$ diet recalls and demographic data were retrieved for participating adolescents. Metabolic syndrome was defined according to paediatric-modified Adult Treatment Panel III criteria. The exposure was defined as a nut intake $\geq 5 \mathrm{~g} / \mathrm{d}$. Setting: USA.

Subjects: Individuals aged 12-19 years ( $n$ 2805).

Results: Nut consumption was associated with lower odds for metabolic syndrome (crude $\mathrm{OR}=0.25 ; 95 \%$ CI $0.11,0.55 ; P \leq 0.001$ ). This effect was independent of age, sex, race/ethnicity and family income:poverty ratio (adjusted OR $=0 \cdot 27 ; 95$ $\%$ CI $0.12,0.61 ; P=0.002$ ), and was stable after controlling for nutritional covariates including intake of sugar and total energy consumption $(\mathrm{OR}=0.36$; $95 \%$ CI $0 \cdot 16,0 \cdot 81 ; P=0 \cdot 014)$.

Conclusion: Nut consumption of $\geq 5 \mathrm{~g} / \mathrm{d}$ is independently associated with lower odds for metabolic syndrome in US adolescents.
\end{abstract}

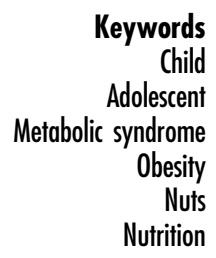

The metabolic syndrome is a co-occurrence of cardiovascular risk factors that identifies patients at increased risk for CVD and type 2 diabetes. It is defined as a combination of increased waist circumference or central obesity, lipid abnormalities typified by elevated TAG or low levels of HDL-cholesterol (HDL-C), abnormal fasting glucose and high blood pressure ${ }^{(1)}$.

Among adolescents, metabolic syndrome has a prevalence of $2-9 \%$ depending on the case definition used $^{(2-4)}$. Several definitions of metabolic syndrome have been used in the literature. Most case definitions include an increase of central adiposity, namely a waist circumference $\geq 90$ th percentile. Dyslipidaemia is part of the definition and can include TAG above $100-110 \mathrm{mg} / \mathrm{dl}$ (1.13-1.24 mmol/1) or HDL-C below 35-40 mg/dl (0.9065$1.036 \mathrm{mmol} / \mathrm{l})$. Elevated blood pressure is also part of the definition and most commonly defined as a systolic or diastolic blood pressure $\geq 90$ th percentile for age, sex and height $^{(1)}$.

Adolescents with metabolic syndrome have higher markers of inflammation and show signs of vascular remodelling as reflected in measurements of carotid intima-media thickness ${ }^{(5-7)}$. Because of the propensity for childhood metabolic risk to track into adulthood ${ }^{(8)}$, there is a great need to identify risk factors for childhood metabolic syndrome which could be targeted through early lifestyle modification.

Dietary items scrutinized for their association with cardiovascular risk in young people have included factors linked to higher risk such as sugary drinks ${ }^{(9,10)}$ and added sugar $^{(11)}$, and those with no effect or lower risk such as fruit juices ${ }^{(12)}$, fibre ${ }^{(13)}$, vegetables and fruits ${ }^{(6,14)}$, and other foods ${ }^{(15)}$. While a link between nut consumption and metabolic health is emerging in adults, little is known about this relationship in adolescents. Interest in nuts as a highly nutritive food found footing with the recognition that an eating pattern rich in nuts is associated with improved health outcomes. A 6-year cohort study of Seventh Day Adventists in California found that higher levels of nut intake were associated with reduced risk of $\mathrm{CHD}^{(16)}$. These findings were subsequently corroborated in different populations of women and men ${ }^{(17-19)}$. Clinical trials of a Mediterranean diet, of which nuts constitute an important part, also indicated a diet rich in their intake has a potential benefit for the prevention of CVD in tertiary and primary prevention ${ }^{(20,21)}$. Candidate nutrients in nuts which are hypothesized to provide a mechanistic link with vascular health include fibre, monounsaturated fats, protein, $\mathrm{Ca}, \mathrm{Mg}$, $\mathrm{Cu}$, phenols and phytosterols ${ }^{(22)}$. Despite the accumulating evidence supporting a role for nuts in a 
healthy diet, little is known about the association between nut intake and cardiovascular risk factors in adolescents. Elucidating this relationship with greater clarity could suggest future avenues for clinical trial design and healthy diet recommendations. The main objective of the present study was to determine whether nut consumption in US adolescents is associated with prevalence of metabolic syndrome.

\section{Participants and methods}

We analysed data from the National Health and Nutrition Examination Survey (NHANES), a study of the health status of children and adults in the USA. The sampling and data collection methods used in NHANES are available online ${ }^{(23)}$. A complex, multistage sampling procedure was used. The USA was divided into primary sampling units which consisted of counties or clusters of counties. Each sampling unit was divided into segments of approximately equal population. The probability of selection of a sampling unit and segment was based on area. Within a segment, households and individuals within households were sampled at a rate to yield a national sample that achieved the desired number of sampled participants for each demographic domain including race/ethnicity, age, sex and income. Oversampling of under-represented minority groups was performed to increase the sampling of groups of particular public health interest, including African Americans, Mexican Americans, low-income White Americans, adolescents, and people over 60 years of age ${ }^{(24)}$. NHANES was approved by the National Center for Health Statistics Institutional Review Board and all participants provided informed consent or assent ${ }^{(25)}$.

We used data from five 2-year cycles from 2003-2004 through 2011-2012. Adolescents were included if they were 12-19 years of age, and excluded if they were pregnant, did not complete the diet survey, did not fast for at least $8 \mathrm{~h}$ or had insufficient data to determine their metabolic syndrome status. Data were extracted from anthropometric measurements, fasting blood tests, $24 \mathrm{~h}$ diet recall surveys and responses pertaining to each participating adolescent's sociodemographic background. Per NHANES protocol, adolescents were weighed on a digital scale while wearing underwear, a paper gown and foam slippers. Height was measured using a fixed stadiometer with a movable headboard. BMI was defined as weight in kilograms divided by the square of height in metres, and for analysis was converted to a $Z$-score specific to each adolescent's age and sex using standards from the Centers for Disease Control and Prevention ${ }^{(26)}$. Waist circumference was measured at the uppermost border of the lateral ilium ${ }^{(27)}$. Blood pressure was obtained after the adolescent was seated for 5 min, using a mercury sphygmomanometer and a digital blood pressure monitor. The blood pressure used for analysis was the average of the last two measurements, or a single measurement if only one was obtained. NHANES laboratories complied with the Clinical Laboratory Improvement Act, and quality control was maintained by random repeat testing performed in a reference laboratory of $2 \%$ of samples as well as split tube parallel testing in practice sessions ${ }^{(28)}$. The $\mathrm{CV}$, an indicator of precision, for this repeat testing of within-assay and between-assay duplicates had to be within $5 \%$ or the specimen was reanalysed $^{(29)}$. Glucose was determined by the glucose oxidase method. HDL-C and TAG were determined by an enzyme-linked colorimetric assay. Assays were performed on a Roche laboratory platform at designated laboratories.

Twenty-four-hour dietary recall data were collected by trained interviewers who first performed an in-person private interview. Children aged 12 years or older provided their own diet recall. To better capture 'usual' dietary intake, a second interview was conducted by telephone 3-10 d later to help reduce intrasubject variability ${ }^{(30)}$. Interviewers were trained in the use of a multiple-pass method to enhance consistency and completeness of data capture. The dietary recall method used by NHANES has been validated ${ }^{(30)}$. Nut intake data were reviewed for plausibility. Nut intake was defined as the average of the nut intake on the two diet recalls.

We defined metabolic syndrome using the paediatric adaptation of the Adult Treatment Panel III guidelines from the National Cholesterol Education Program ${ }^{(31,32)}$. Specifically, metabolic syndrome occurred when three or more of the following were present: waist circumference $\geq 90$ th percentile for race, age and $\operatorname{sex}^{(33)}$, HDL-C $<40 \mathrm{mg} / \mathrm{dl}$ $(1.036 \mathrm{mmol} / \mathrm{l})$, TAG $\geq 110 \mathrm{mg} / \mathrm{dl}(1.24 \mathrm{mmol} / \mathrm{l})$, fasting glucose $\geq 100 \mathrm{mg} / \mathrm{dl}(5.5 \mathrm{mmol} / \mathrm{l})$ and/or elevated blood pressure defined as systolic or diastolic blood pressure $\geq 90$ th percentile normalized for age, height and $\operatorname{sex}^{(34)}$.

Because of their nutritional similarity and phylogenetic overlap, both nuts (tree nuts and peanuts) and seeds were included in the daily intake total. For clarity they are referred to simply as 'nuts' unless otherwise specified. Nut and seed butters were included as part of the total daily consumption. Nuts and seeds found in candy bars or other sweets were not included. For analytic purposes, nut exposure was defined as an intake of $\geq 5 \mathrm{~g} / \mathrm{d}$, which was the mean intake.

\section{Statistical analysis}

Analyses were performed according to published NHANES analytic guidelines using the SURVEY procedures in the statistical software package SAS version 9.4. To adjust the weights of the analytic sample to reflect its definition as the intersection of two sub-samples, a propensity score was calculated for inclusion in the analytic sample predicted by demographic variables; the inverse of 
the propensity score was multiplied by the fasting laboratory sub-sample weight to produce a final analytic sample weight ${ }^{(35)}$. Descriptive statistics, including means, standard errors and percentages, were computed with analytic sample weights. Weighted logistic regression was used to assess the association of metabolic syndrome with nut consumption $\geq 5 \mathrm{~g} / \mathrm{d}$ after adjustment for demographic, clinical and dietary variables. Nutrients and macronutrients in the model were treated as continuous variables. Demographic, clinical and dietary variables were selected for inclusion in the adjusted models model based on hypothesized clinical relevance and tested for multicollinearity prior to inclusion. Interaction effects between nut consumption and demographic variables were entered into the model and removed if not statistically significant with a significance criterion of $0 \cdot 05$. All main effects were included in the final models. Unadjusted and adjusted odds ratios with $95 \%$ confidence intervals were presented. All tests were two-tailed and performed at a significance level of $0 \cdot 05$.

\section{Results}

\section{Study population}

There were 50912 individuals in the NHANES database from years 2003-2012, of whom 8360 were non-pregnant and aged 12-19 years. Following exclusions for not fasting, incomplete diet information or indeterminate metabolic syndrome status, the remaining 2805 adolescents constituted the analytic sample. We compared the analytic sample with the excluded adolescents and found no significant differences in their age, sex, BMI or metabolic syndrome prevalence (data not shown). The excluded sample had a mean nut intake of $4 \mathrm{~g} / \mathrm{d}$ compared with $5 \mathrm{~g} / \mathrm{d}$ in the analytic sample $(P=0 \cdot 021)$.

\section{Factors associated with nut consumption $\geq 5 \mathrm{~g} / \mathrm{d}$}

We then compared anthropometric, biochemical and demographic traits in adolescents consuming nuts $\geq 5 \mathrm{~g} / \mathrm{d}$ $v$. those eating $<5 \mathrm{~g} / \mathrm{d}$. The prevalence of metabolic syndrome was higher in those eating $<5 \mathrm{~g} / \mathrm{d}(8 v .2 \%$, $P<0.001)$. Adolescents eating nuts $\geq 5 \mathrm{~g} / \mathrm{d}$ were more likely non-Hispanic White, had higher income:poverty ratio, and had greater intakes of sugar, energy, fibre, total fat, SFA, MUFA and PUFA (Table 1).

\section{Logistic regression}

Using logistic regression, the odds for metabolic syndrome was determined for sociodemographic and dietary factors. Of these, nut intake $\geq 5 \mathrm{~g} / \mathrm{d}$, sex (female $v$. male), race/ ethnicity (Black $v$. White) and family income:poverty ratio were significantly associated with metabolic syndrome risk (Table 2). Interaction terms for race and nut intake were not significant (data not shown).

\section{Metabolic syndrome and nut intake}

Adolescents who ate nuts $\geq 5 \mathrm{~g} / \mathrm{d}$ had lower odds for metabolic syndrome compared with those eating lesser amounts (unadjusted OR $=0.25 ; 95 \%$ CI 0.11, 0.55; $P<0 \cdot 001$ ). Because of the known relationship between metabolic syndrome and sociodemographic and dietary factors, we generated additional models in which we adjusted for pertinent covariates. In Model 2, we adjusted for age, sex, race/ethnicity and family income:poverty ratio. In Model 3, we added adjustments for dietary factors including intakes of sugar, fat, SFA, fibre, fruits and vegetables. Model 4 included factors from Model 2, plus intakes of sugar, fat and protein as percentages of total energy. The models are shown in Table 2.

Because physical activity could confound the association between nut intake and metabolic syndrome, we repeated the analysis while limiting the sample to the NHANES cycle years in which physical activity data were uniformly and quantitatively collected (2007-2012). We designated as physically active those adolescents who reported performing work or recreational physical activity of moderate or vigorous intensity for $\geq 150 \mathrm{~min} /$ week. Inclusion of this measure of physical activity into the adjusted model continued to show a significantly lower odds of metabolic syndrome associated with nut intake $\geq 5 \mathrm{~g} / \mathrm{d}$ (Table 3 ). Because BMI $Z$-score was highly correlated with metabolic syndrome, as well as nut intake, we tested for interaction by adding an interaction term to the unadjusted and adjusted regression models. No evidence for interaction was found (data not shown).

\section{Nut intake in US adolescents}

Because nut consumption was associated with metabolic syndrome status, we examined nut consumption patterns in US adolescents. Mean daily nut intake was 5 (SE 0.48) $\mathrm{g} / \mathrm{d}$. The median and 75 th percentile of nut intake was zero. Eighty per cent of all participants ate no nuts at all. Among those eating any nuts, median intake was $8.0 \mathrm{~g} / \mathrm{d}$. Overall, these indicated a highly skewed distribution of nut intake.

\section{Discussion}

In US adolescents, we found that nut consumption $\geq 5 \mathrm{~g} / \mathrm{d}$ is associated with lower odds for metabolic syndrome. This relationship remained significant after controlling for age, sex, race/ethnicity, household income, and several dietary characteristics including sugar, total energy, fruit and vegetable intakes. We also found that nut intake is low among adolescents and a majority reported consuming no nuts at all during the interview days. We found that all races/ethnicities and both sexes ate few nuts. Nut intake was associated with lower odds for metabolic syndrome in Blacks $v$. Whites, and higher odds for Mexican Americans 
Table 1 Data summaries, overall and by nut intake, among US adolescents aged 12-19 years ( $n$ 2805), National Health and Nutrition Examination Survey (NHANES) 2003-2012

\begin{tabular}{|c|c|c|c|c|c|c|c|c|c|c|}
\hline \multirow[b]{2}{*}{ Factor } & \multicolumn{3}{|c|}{ Overall } & \multicolumn{3}{|c|}{ Nut intake $<5 \mathrm{~g} / \mathrm{d}$} & \multicolumn{3}{|c|}{ Nut intake $\geq 5 \mathrm{~g} / \mathrm{d}$} & \multirow[b]{2}{*}{$P$ value } \\
\hline & $n$ & $\begin{array}{l}\text { Mean } \\
\text { or } \%\end{array}$ & SE & $n$ & $\begin{array}{c}\text { Mean } \\
\text { or } \%\end{array}$ & SE & $n$ & $\begin{array}{c}\text { Mean } \\
\text { or } \%\end{array}$ & SE & \\
\hline Nut intake $(\mathrm{g} / \mathrm{d})$ & 2805 & $5 \cdot 0$ & 0.48 & 2434 & 0.07 & 0.01 & 371 & $28 \cdot 6$ & 2.00 & $<0.001$ \\
\hline Metabolic syndrome (\%) & 2805 & 7 & & 2434 & 8 & & 371 & 2 & & $<0.001$ \\
\hline Age (years) & 2805 & $15 \cdot 0$ & 0.06 & 2434 & $15 \cdot 5$ & 0.06 & 371 & $15 \cdot 3$ & 0.14 & $0 \cdot 18$ \\
\hline Sex & 2805 & & & 2434 & & & 371 & & & 0.94 \\
\hline Male (\%) & & 52 & & & 52 & & & 52 & & \\
\hline Female (\%) & & 48 & & & 48 & & & 48 & & \\
\hline Race/ethnicity & 2805 & & & 2434 & & & 371 & & & $<0.001$ \\
\hline Non-Hispanic White (\%) & & 61 & & & 58 & & & 73 & & \\
\hline Non-Hispanic Black (\%) & & 15 & & & 16 & & & 9 & & \\
\hline Mexican American (\%) & & 12 & & & 13 & & & 8 & & \\
\hline Other race (\%) & & 12 & & & 13 & & & 10 & & \\
\hline Family income:poverty ratio & 2646 & 2.6 & 0.07 & 2292 & 2.5 & 0.07 & 354 & 3.07 & 0.15 & $<0.001$ \\
\hline Total sugars $(\mathrm{g} / \mathrm{d})$ & 2805 & 132 & 1.68 & 2434 & 131 & 1.85 & 371 & 140 & $4 \cdot 12$ & 0.032 \\
\hline Total sugars ( $\%$ of total energy) & 2805 & $25 \cdot 2$ & 0.20 & 2434 & $25 \cdot 3$ & 0.23 & 371 & $24 \cdot 7$ & 0.50 & 0.27 \\
\hline Energy $(\mathrm{kJ} / \mathrm{d})$ & 2805 & 8828 & $96 \cdot 15$ & 2434 & 8665 & 99.70 & 371 & 9602 & $246 \cdot 86$ & $<0.001$ \\
\hline Energy (kcal/d) & 2805 & 2110 & 22.98 & 2434 & 2071 & 23.83 & 371 & 2295 & $59 \cdot 00$ & $<0.001$ \\
\hline Total fat $(\mathrm{g} / \mathrm{d})$ & 2805 & 78 & 1.02 & 2434 & 76 & 1.08 & 371 & 87 & 2.64 & $<0.001$ \\
\hline Total fat (\% of total energy) & 2805 & 33 & 0.20 & 2434 & 33 & 0.22 & 371 & 34 & 0.47 & 0.034 \\
\hline Total SFA (g/d) & 2805 & 27 & 0.36 & 2434 & 26 & 0.38 & 371 & 29 & 0.92 & 0.012 \\
\hline Total SFA ( $\%$ of total energy) & 2805 & 11.2 & 0.08 & 2434 & 11.3 & 0.08 & 371 & $11 \cdot 1$ & 0.19 & 0.46 \\
\hline Total MUFA (g/d) & 2805 & 28 & 0.40 & 2434 & 27 & 0.41 & 371 & 32 & 1.09 & $<0.001$ \\
\hline Total MUFA (\% of total energy) & 2805 & 11.9 & 0.09 & 2434 & 11.8 & $0 \cdot 10$ & 371 & 12.4 & 0.20 & 0.017 \\
\hline Total PUFA (g/d) & 2805 & 16 & 0.25 & 2434 & 16 & 0.27 & 371 & 20 & 0.59 & $<0.001$ \\
\hline Total PUFA ( $\%$ of total energy) & 2805 & 7 & 0.07 & 2434 & 7 & 0.07 & 371 & 8 & $0 \cdot 17$ & $<0.001$ \\
\hline Dietary fibre $(\mathrm{g} / \mathrm{d})$ & 2805 & 14 & 0.28 & 2434 & 13 & 0.27 & 371 & 18 & 0.59 & $<0.001$ \\
\hline Protein $(\mathrm{g} / \mathrm{d})$ & 2805 & 78 & 0.97 & 2434 & 77 & 1.04 & 371 & 83 & $2 \cdot 22$ & 0.009 \\
\hline Protein (\% of total energy) & 2805 & $15 \cdot 0$ & 0.10 & 2434 & $15 \cdot 0$ & 0.11 & 371 & 14.6 & 0.20 & 0.033 \\
\hline $\mathrm{Na}(\mathrm{g} / \mathrm{d})$ & 2805 & $6 \cdot 8$ & 0.08 & 2434 & $6 \cdot 8$ & 0.09 & 371 & $7 \cdot 0$ & $0 \cdot 19$ & 0.29 \\
\hline Total no. of fruit cup-equivalents & 2805 & 0.90 & 0.03 & 2063 & 0.86 & 0.03 & 307 & $1 \cdot 1$ & 0.06 & 0.002 \\
\hline Total no. of vegetable cup-equivalents & 2805 & 1.1 & 0.03 & 2063 & $1 \cdot 1$ & 0.03 & 307 & 1.0 & 0.05 & 0.20 \\
\hline Added sugars (teaspoon-equivalents) & 2805 & $20 \cdot 0$ & 0.33 & 2063 & $20 \cdot 0$ & 0.38 & 307 & $19 \cdot 7$ & 0.84 & 0.76 \\
\hline BMI-for-age Z-score & 2800 & 0.52 & 0.03 & 2430 & 0.58 & 0.03 & 370 & 0.29 & 0.07 & $<0.001$ \\
\hline Waist circumference (percentile) & 2455 & 0.87 & 0.01 & 2122 & 0.87 & 0.01 & 333 & 0.84 & 0.01 & $<0.001$ \\
\hline Systolic blood pressure (percentile) & 2805 & 43 & $1 \cdot 10$ & 2434 & 44 & $1 \cdot 15$ & 371 & 39 & 1.97 & 0.003 \\
\hline Diastolic blood pressure (percentile) & 2805 & 37 & 1.08 & 2434 & 37 & 1.09 & 371 & 35 & 1.94 & 0.25 \\
\hline Direct HDL-cholesterol (mmol/l) & 2805 & 1.4 & 0.01 & 2434 & 1.3 & 0.01 & 371 & 1.4 & 0.02 & 0.002 \\
\hline TAG $(\mathrm{mmol} / \mathrm{l})$ & 2805 & 0.98 & 0.02 & 2434 & 0.98 & 0.02 & 371 & 0.94 & 0.03 & 0.20 \\
\hline Plasma glucose $(\mathrm{mmol} / \mathrm{l})$ & 2805 & $5 \cdot 2$ & 0.02 & 2434 & $5 \cdot 2$ & 0.02 & 371 & $5 \cdot 2$ & 0.07 & 0.78 \\
\hline
\end{tabular}

Descriptive statistics were computed with analytic sample weights (weights $=$ fasting weights $\times 1 /$ propensity score).

$P$ values were obtained from weighted univariable logistic regression models; significant $P$ values are indicated in bold font.

$v$. Whites; however, the number of individuals in each subgroup was small, which should temper overinterpretation of these differences. Females and those with higher income:poverty ratio also had lower odds for metabolic syndrome. Overall, our finding that a small amount of daily nut intake is associated with lower odds of metabolic syndrome in adolescents was still significant after controlling for pertinent dietary, lifestyle and sociodemographic characteristics.

The present study has several limitations. First, because it is a cross-sectional study, the findings are correlative and from them one cannot infer causation. Second, although we adjusted for important covariates, residual confounding cannot be excluded. However, we did attempt to control for dietary practices that could covary with nut intake, for example as part of a healthy eating pattern and lifestyle. To this end we included intakes of fruits, vegetables, fibre, fat, saturated fat, total energy and physical activity. Third, in the current analysis we were not able to ascertain if there were specific types of nuts or seeds that were more strongly associated with metabolic well-being. However, the published literature suggests that health benefits are observed with a range of types including peanuts, walnuts, almonds, pistachios and others. The use of $24 \mathrm{~h}$ diet recalls has been criticized as not capturing usual intake compared with other methods, such as FFQ. However, it also has advantages over competing methods in that it is open-ended, tends to be more quantitative, and requires less recall of foods eaten weeks and months before the assessment. Moreover, using two $24 \mathrm{~h}$ diet recalls as we did captures usual intake more accurately than a single survey and reduces intrasubject variability ${ }^{(36)}$.

In adults, nut consumption has been linked with several positive health outcomes ${ }^{(17-19,37,38)}$. In large cohort studies, greater nut consumption is associated with a lower risk for sudden cardiac death ${ }^{(19)}$, myocardial infarction ${ }^{(17)}$, metabolic syndrome ${ }^{(37)}$ and diabetes ${ }^{(39,40)}$. Nuts are a major component of the Mediterranean diet, which has 
Table 2 Logistic models of factors associated with metabolic syndrome among US adolescents aged 12-19 years ( $n$ 2805), National Health and Nutrition Examination Survey (NHANES) 2003-2012

\begin{tabular}{|c|c|c|c|}
\hline Effect & $n$ & OR & $95 \% \mathrm{Cl}$ \\
\hline Model 1 & 2805 & & \\
\hline Nut intake $\geq 5 \mathrm{~g} / \mathrm{d}$ : yes $v$. no & & 0.254 & $0.115,0.551$ \\
\hline Model 2 & $2646^{*}$ & & \\
\hline Nut intake $\geq 5 \mathrm{~g} / \mathrm{d}$ : yes $v$. no & & 0.271 & $0.121,0.610$ \\
\hline Sex: female $v$. male & & 0.547 & $0.355,0.843$ \\
\hline Race/ethnicity: Black $v$. White & & 0.526 & $0.295,0.936$ \\
\hline $\begin{array}{l}\text { Race/ethnicity: Mexican } \\
\text { American } v \text {. White }\end{array}$ & & 1.642 & $0.976,2.763$ \\
\hline Race/ethnicity: Other $v$. White & & 0.962 & $0.520,1.781$ \\
\hline Age & & 1.021 & $0.938,1.110$ \\
\hline Family income:poverty ratio & & 0.843 & $0.734,0.968$ \\
\hline Model 3 & $2646^{\star}$ & & \\
\hline Nut intake $\geq 5 \mathrm{~g} / \mathrm{d}$ : yes $v$. no & & 0.288 & $0.134,0.621$ \\
\hline Sex: female $v$. male & & 0.472 & $0.283,0.787$ \\
\hline Race/ethnicity: Black $v$. White & & 0.445 & $0.247,0.802$ \\
\hline $\begin{array}{l}\text { Race/ethnicity: Mexican } \\
\text { American } v \text {. White }\end{array}$ & & $1 \cdot 766$ & $1.059,2.944$ \\
\hline Race/ethnicity: Other $v$. White & & 1.029 & $0.534,1.982$ \\
\hline Age & & 1.036 & $0.949,1.130$ \\
\hline Family income:poverty ratio & & 0.843 & $0.729,0.974$ \\
\hline Total energy (kcal) & & 0.998 & $0.997,1.000$ \\
\hline Total sugar (g/d) & & 1.008 & $1.001,1.014$ \\
\hline Total MǓFA (g/d) & & 1.035 & $0.999,1.073$ \\
\hline Dietary fibre $(\mathrm{g} / \mathrm{d})$ & & 1.019 & $0.975,1.065$ \\
\hline Protein $(\mathrm{g} / \mathrm{d})$ & & 1.005 & $0.992,1.018$ \\
\hline $\mathrm{Na}(\mathrm{g} / \mathrm{d})$ & & 1.068 & $0.955,1.194$ \\
\hline Total no. of fruit cup-equivalents & & 0.801 & $0.648,0.990$ \\
\hline $\begin{array}{l}\text { Total no. of vegetable cup- } \\
\text { equivalents }\end{array}$ & & 1.013 & $0.792,1.295$ \\
\hline Model 4 & $2646^{*}$ & & \\
\hline Nut intake $\geq 5 \mathrm{~g} / \mathrm{d}$ : yes $v$. no & & 0.275 & $0.124,0.613$ \\
\hline Sex: female $v$. male & & 0.536 & $0.342,0.840$ \\
\hline Race/ethnicity: Black $v$. White & & 0.426 & $0.233,0.779$ \\
\hline $\begin{array}{l}\text { Race/ethnicity: Mexican } \\
\text { American } v \text {. White }\end{array}$ & & 1.623 & $0.958,2.749$ \\
\hline Race/ethnicity: Other $v$. White & & 0.950 & $0.482,1.873$ \\
\hline Age & & 1.028 & $0.943,1.122$ \\
\hline Family income:poverty ratio & & 0.840 & $0.730,0.967$ \\
\hline Total sugar ( $\%$ of total energy) & & 1.019 & $0.983,1.056$ \\
\hline Total fat ( $\%$ of total energy) & & 1.012 & $0.971,1.054$ \\
\hline Protein ( $\%$ of total energy) & & 1.009 & $0.952,1.070$ \\
\hline
\end{tabular}

Models were computed with analytic sample weights (weights = fasting weights $\times 1$ propensity score).

Model 1: unadjusted OR.

Model 2: adjusted for age, sex, race/ethnicity and income:poverty ratio.

Model 3: includes Model 2 plus intakes of sugar, Na, PUFA, fibre, fruits and vegetables, protein and total energy.

Model 4: includes Model 2 plus sugar, fat and protein as percentages of total energy.

*Missing data on income:poverty ratio.

been shown to result in a $30 \%$ reduction in combined cardiovascular morbidity in a primary prevention trial ${ }^{(21)}$.

In contrast to the literature available in adults, the relationship between nut consumption and cardiometabolic risk factors in children and adolescents has received scant attention in the literature, and the published reports have been limited with respect to age group, geographic location or $\operatorname{sex}^{(41,42)}$. O'Neil et al. found that nut intake greater than $7 \cdot 1 \mathrm{~g} / \mathrm{d}$ correlated with higher daily intakes of energy, MUFA, PUFA, fruits and vegetables. Among adolescents in their study, nut intake above $7 \cdot 1 \mathrm{~g} / \mathrm{d}$ was associated with lower body weight and a lower
Table 3 Crude and adjusted odds ratios for metabolic syndrome among adolescents consuming nuts $\geq 5 \mathrm{~g} / \mathrm{d}$ compared with nonconsumers in those with available physical activity data: US adolescents aged $12-19$ years ( $n$ 2805), National Health and Nutrition Examination Survey (NHANES) 2003-2012

\begin{tabular}{llcc}
\hline & $n$ & OR & $95 \% \mathrm{Cl}$ \\
\hline Model 1 & 1240 & 0.136 & $0.047,0.387$ \\
Model 2 & $1147^{\star}$ & 0.183 & $0.062,0.545$ \\
Model 3 & $1147^{\star}$ & 0.196 & $0.068,0.565$ \\
Model 4 & $1147^{\star}$ & 0.187 & $0.062,0.564$ \\
\hline
\end{tabular}

Models were computed with analytic sample weights (weights = fasting weights $\times 1$ /propensity score).

Model 1: unadjusted OR.

Model 2: adjusted for age, sex, race/ethnicity, income:poverty ratio and physical activity $\geq 150 \mathrm{~min} /$ week

Model 3: includes Model 2 plus intakes of sugar, Na, PUFA, fibre, fruits and vegetables, protein and total energy, and physical activity $\geq 150 \mathrm{~min} /$ week. Model 4: includes Model 2 plus sugar, fat and protein as percentages of total energy, and physical activity $\geq 150 \mathrm{~min} /$ week.

${ }^{*}$ Missing data on income:poverty ratio.

prevalence of overweight or obese status. The study was limited however by use of only a single day's dietary recall, finding only a small number of adolescents with a nut intake above $7 \cdot 1 \mathrm{~g} / \mathrm{d}$, not appropriately reporting blood pressure as a percentage based on height, weight and sex, and lack of biochemical data in any nonadults $^{(43)}$. Therefore, our study goes beyond previous findings, fills a significant knowledge gap, and is the first to examine the relationship between nut consumption and metabolic syndrome in adolescents.

Nielsen et al. have reported that $40 \%$ of nuts consumed by children aged $2-19$ years is as isolated nuts, whereas about $60 \%$ comes in a combination such as in baked grain products like cakes or cookies, in candy, or mixed in with other foods such as ice cream, cheese or other food items ${ }^{(44)}$. We omitted nuts consumed in these mixed forms since these foods tend to be high in sugar, fat and energy. Concern about allergies could be a factor limiting nut intake in children; however, recent advances may lessen fears about childhood nut allergies in the future.

Mechanistically, nutrients within nuts appear to modify circulating cardiometabolic risk factors. Human trials have shown that nut consumption is linked to reduced fasting insulin ${ }^{(45)}$ and glucose ${ }^{(46)}$, and an improved lipid profile ${ }^{(47)}$. These effects may be mediated by their high concentrations of polyphenols and mono- and polyunsaturated fatty acids ${ }^{(48,49)}$. Pistachios, for example, have been found to enhance endothelial function ${ }^{(50)}$, lower inflammation $^{(51)}$, reduce atherogenic LDL-cholesterol ${ }^{(52)}$, and improve blood pressure and measures of heart rate variability ${ }^{(53)}$. Walnuts exhibit similar attributes, improving lipids ${ }^{(54)}$ and enhancing endothelial function as assessed by flow mediated dilation ${ }^{(55)}$. The vascular benefits in particular could be mediated by their constituent polyphenols, the urinary excretion of which has been shown to correlate with plasma nitric oxide ${ }^{(56)}$. Nuts are also relatively high in fibre, which may improve glucose homeostasis and satiety ${ }^{(57)}$. The nut consumers in our 
study had significantly higher intakes of MUFA, PUFA and fibre, in comparison to non-consumers.

Nut consumers had a significantly higher daily energy intake compared with non-eaters yet had a significantly lower BMI $Z$-score, a finding not previously reported in adolescents $^{(43)}$. As metabolic syndrome prevalence increases with BMI, it would be reasonable to surmise that BMI may mediate favourable health outcomes associated with nut consumption. Our analysis did not support this however, since a test for interaction between BMI $Z$-score and nut intake $v$. the odds of metabolic syndrome was nonsignificant in all regression models. Moreover, after controlling for potential lifestyle confounders including dietary sugar, fruit and vegetable intakes, total energy and physical activity, we found that the adjusted odds for metabolic syndrome remained significant. Potential mechanisms for nut eaters to have a lower BMI include increased energy expenditure and incomplete energy absorption ${ }^{(58)}$; however, these hypotheses require further study.

In summary, greater nut consumption among adolescents is associated with lower odds for metabolic syndrome and an improved cardiovascular risk factor profile. Despite the growing literature supporting the health benefits of nuts, most adolescents consume no or very few nuts each day. Prospective research is needed to determine whether promotion of nut consumption among adolescents would result in improved health outcomes.

\section{Acknowledgements}

Acknowledgements: The authors acknowledge Anne Tang for support with data acquisition and analysis. Financial support: This research received no specific grant from any funding agency in the public, commercial or not-for-profit sectors. Conflicts of interest: None. Authorship: R.J.K. developed the hypothesis and research plan, contributed to data acquisition and analysis, and had primary responsibility for writing and the final content. S.W., L.W. and D.L. retrieved the data and performed statistical analysis. All authors contributed to writing and approved the final manuscript. Ethics of human subject participation: This study was conducted according to the guidelines laid down in the Declaration of Helsinki and all procedures involving human subjects were approved by the Institutional Review Board of the National Center for Health Statistics. Written informed consent or assent was obtained from all subjects.

\section{References}

1. Zimmet P, Alberti KG, Kaufman F et al. (2007) The metabolic syndrome in children and adolescents - an IDF consensus report. Pediatr Diabetes 8, 299-306.

2. Cook S, Auinger P, Li C et al. (2008) Metabolic syndrome rates in United States adolescents, from the National Health and Nutrition Examination Survey, 1999-2002. J Pediatr 152, $165-170$.

3. Ford ES, Li C, Zhao G et al. (2008) Prevalence of the metabolic syndrome among US adolescents using the definition from the International Diabetes Federation. Diabetes Care 31, 587-589.

4. de Ferranti SD, Gauvreau K, Ludwig DS et al. (2004) Prevalence of the metabolic syndrome in American adolescents: findings from the Third National Health and Nutrition Examination Survey. Circulation 110, 2494-2497.

5. Ford ES, Ajani UA \& Mokdad AH (2005) The metabolic syndrome and concentrations of C-reactive protein among US youth. Diabetes Care 28, 878-881.

6. Pan Y \& Pratt CA (2008) Metabolic syndrome and its association with diet and physical activity in US adolescents. J Am Diet Assoc 108, 276-286.

7. Toledo-Corral CM, Ventura EE, Hodis HN et al. (2009) Persistence of the metabolic syndrome and its influence on carotid artery intima media thickness in overweight Latino children. Atherosclerosis 206, 594-598.

8. Magnussen CG, Raitakari OT, Thomson R et al. (2008) Utility of currently recommended pediatric dyslipidemia classifications in predicting dyslipidemia in adulthood: evidence from the Childhood Determinants of Adult Health (CDAH) study, Cardiovascular Risk in Young Finns Study, and Bogalusa Heart Study. Circulation 117, 32-42.

9. Kosova EC, Auinger P \& Bremer AA (2013) The relationships between sugar-sweetened beverage intake and cardiometabolic markers in young children. J Acad Nutr Diet 113, 219-227.

10. Ambrosini GL, Oddy WH, Huang RC et al. (2013) Prospective associations between sugar-sweetened beverage intakes and cardiometabolic risk factors in adolescents. $\mathrm{Am} \mathrm{J}$ Clin Nutr 98, 327-334.

11. Rodriguez LA, Madsen KA, Cotterman C et al. (2016) Added sugar intake and metabolic syndrome in US adolescents: cross-sectional analysis of the National Health and Nutrition Examination Survey 2005-2012. Public Health Nutr 19, 2424-2434.

12. Wang Y, Lloyd B, Yang M et al. (2012) Impact of orange juice consumption on macronutrient and energy intakes and body composition in the US population. Public Health Nutr 15, 2220-2227.

13. Carlson JJ, Eisenmann JC, Norman GJ et al. (2011) Dietary fiber and nutrient density are inversely associated with the metabolic syndrome in US adolescents. J Am Diet Assoc 111, 1688-1695.

14. Yoo S, Nicklas T, Baranowski T et al. (2004) Comparison of dietary intakes associated with metabolic syndrome risk factors in young adults: the Bogalusa Heart Study. Am J Clin Nutr 80, 841-848.

15. O'Neil CE, Nicklas TA, Zanovec M et al. (2011) Consumption of whole grains is associated with improved diet quality and nutrient intake in children and adolescents: the National Health and Nutrition Examination Survey 1999-2004. Public Health Nutr 14, 347-355.

16. Fraser GE, Sabate J, Beeson WL et al. (1992) A possible protective effect of nut consumption on risk of coronary heart disease. The Adventist Health Study. Arch Intern Med 152, 1416-1424.

17. Hu FB, Stampfer MJ, Manson JE et al. (1998) Frequent nut consumption and risk of coronary heart disease in women: prospective cohort study. BMJ 317, 1341-1345.

18. Ellsworth JL, Kushi LH \& Folsom AR (2001) Frequent nut intake and risk of death from coronary heart disease and all causes in postmenopausal women: the Iowa Women's Health Study. Nutr Metab Cardiovasc Dis 11, 372-377.

19. Albert CM, Gaziano JM, Willett WC et al. (2002) Nut consumption and decreased risk of sudden cardiac death in the Physicians' Health Study. Arch Intern Med 162, 1382-1387. 
20. de Lorgeril M, Salen P, Martin JL et al. (1999) Mediterranean diet, traditional risk factors, and the rate of cardiovascular complications after myocardial infarction: final report of the Lyon Diet Heart Study. Circulation 99, 779-785.

21. Estruch R, Ros E, Salas-Salvado J et al. (2013) Primary prevention of cardiovascular disease with a Mediterranean diet. N Engl J Med 368, 1279-1290.

22. Ros E (2010) Health benefits of nut consumption. Nutrients 2, 652-682.

23. Centers for Disease Control and Prevention, National Center for Health Statistics (2017) National Health and Nutrition Examination Survey. http://www.cdc.gov/nchs/nhanes.htm (accessed September 2017).

24. Johnson CL, Dohrmann SM, Burt VL et al. (2014) National health and nutrition examination survey: sample design, 2011-2014. Vital Health Stat 2 issue162, 1-33.

25. Centers for Disease Control and Prevention, National Center for Health Statistics (2015) NCHS Research Ethics Review Board (ERB) Approval. http://www.cdc.gov/nchs/nhanes/ irba98.htm (accessed September 2017).

26. Kuczmarski RJ, Ogden CL, Guo SS et al. (2002) 2000 CDC Growth Charts for the United States: methods and development. Vital Health Stat 11 issue 246, 1-190.

27. Centers for Disease Control and Prevention, National Center for Health Statistics (2000) National Health and Nutrition Examination Survey: Anthropometry Procedures Manual. http://www.cdc.gov/nchs/data/nhanes/bm.pdf (accessed September 2017).

28. Centers for Disease Control and Prevention, National Center for Health Statistics (2013-2014) National Health and Nutrition Examination Survey: 2013-2014 Survey Operations Manuals. https://wwwn.cdc.gov/nchs/nhanes/ continuousnhanes/manuals.aspx?BeginYear=2013 (accessed September 2017)

29. Centers for Disease Control and Prevention, National Center for Health Statistics (2004) National Health and Nutrition Examination Survey: 2003-2004 Laboratory Procedure Manual (Glucose). https://www.cdc.gov/nchs/data/ nhanes/nhanes_03_04/110am_c_met_glucose.pdf (accessed August 2018).

30. Ahluwalia N, Dwyer J, Terry A et al. (2016) Update on NHANES dietary data: focus on collection, release, analytical considerations, and uses to inform public policy. Adv Nutr 7, 121-134.

31. Li C, Ford ES, McBride PE et al. (2011) Non-high-density lipoprotein cholesterol concentration is associated with the metabolic syndrome among US youth aged 12-19 years. J Pediatr 158, 201-207.

32. Cook S, Weitzman M, Auinger P et al. (2003) Prevalence of a metabolic syndrome phenotype in adolescents: findings from the Third National Health and Nutrition Examination Survey, 1988-1994. Arch Pediatr Adolesc Med 157, 821-827.

33. Fernandez JR, Redden DT, Pietrobelli A et al. (2004) Waist circumference percentiles in nationally representative samples of African-American, European-American, and Mexican-American children and adolescents. J Pediatr 145, 439-444.

34. National High Blood Pressure Education Program Working Group on High Blood Pressure in Children and Adolescents (2004) The fourth report on the diagnosis, evaluation, and treatment of high blood pressure in children and adolescents. Pediatrics 114, 2 Suppl. 4th Report, 555-576.

35. Tilert T, Dillon C, Paulose-Ram R et al. (2013) Estimating the US prevalence of chronic obstructive pulmonary disease using pre- and post-bronchodilator spirometry: the National Health and Nutrition Examination Survey (NHANES) 20072010. Respir Res 14, 103.

36. Shim J-S, Oh K \& Kim HC (2014) Dietary assessment methods in epidemiologic studies. Epidemiol Health 36, e2014009.
37. Jaceldo-Siegl K, Haddad E, Oda K et al. (2014) Tree nuts are inversely associated with metabolic syndrome and obesity: the Adventist Health Study-2. PLoS One 9, e85133.

38. Brown RC, Tey SL, Gray AR et al. (2015) Association of nut consumption with cardiometabolic risk factors in the 2008/2009 New Zealand Adult Nutrition Survey. Nutrients 7, 7523-7542.

39. Jiang R, Manson JE, Stampfer MJ et al. (2002) Nut and peanut butter consumption and risk of type 2 diabetes in women. JAMA 288, 2554-2560.

40. Kochar J, Gaziano JM \& Djousse L (2010) Nut consumption and risk of type II diabetes in the Physicians' Health Study. Eur J Clin Nutr 64, 75-79.

41. Moreno JP, Johnston CA, El-Mubasher AA et al. (2013) Peanut consumption in adolescents is associated with improved weight status. Nutr Res 33, 552-556.

42. Maranhao PA, Kraemer-Aguiar LG, de Oliveira CL et al. (2011) Brazil nuts intake improves lipid profile, oxidative stress and microvascular function in obese adolescents: a randomized controlled trial. Nutr Metab (Lond) 8, 32.

43. O'Neil CE, Keast DR, Nicklas TA et al. (2012) Out-of-hand nut consumption is associated with improved nutrient intake and health risk markers in US children and adults: National Health and Nutrition Examination Survey 1999-2004. Nutr Res 32, 185-194.

44. Nielsen SJ, Herrick KA, Akinbami LJ et al. (2016) Nut consumption among US youth, 2009-2012. NCHS Data Brief issue $238,1-8$.

45. Tapsell LC, Batterham MJ, Teuss G et al. (2009) Long-term effects of increased dietary polyunsaturated fat from walnuts on metabolic parameters in type II diabetes. Eur J Clin Nutr 63, 1008-1015.

46. Parham M, Heidari S, Khorramirad A et al. (2014) Effects of pistachio nut supplementation on blood glucose in patients with type 2 diabetes: a randomized crossover trial. Rev Diabet Stud 11, 190-196.

47. Mercanligil SM, Arslan P, Alasalvar C et al. (2007) Effects of hazelnut-enriched diet on plasma cholesterol and lipoprotein profiles in hypercholesterolemic adult men. Eur J Clin Nutr 61, 212-220.

48. Dominguez-Avila JA, Alvarez-Parrilla E, Lopez-Diaz JA et al. (2015) The pecan nut (Carya illinoinensis) and its oil and polyphenolic fractions differentially modulate lipid metabolism and the antioxidant enzyme activities in rats fed high-fat diets. Food Chem 168, 529-537.

49. Jones PJ, Jew S \& AbuMweis S (2008) The effect of dietary oleic, linoleic, and linolenic acids on fat oxidation and energy expenditure in healthy men. Metabolism 57, 1198-1203.

50. Kendall CW, West SG, Augustin LS et al. (2014) Acute effects of pistachio consumption on glucose and insulin, satiety hormones and endothelial function in the metabolic syndrome. Eur J Clin Nutr 68, 370-375.

51. Gulati S, Misra A, Pandey RM et al. (2014) Effects of pistachio nuts on body composition, metabolic, inflammatory and oxidative stress parameters in Asian Indians with metabolic syndrome: a $24-\mathrm{wk}$, randomized control trial. Nutrition 30, 192-197.

52. Holligan SD, West SG, Gebauer SK et al. (2014) A moderatefat diet containing pistachios improves emerging markers of cardiometabolic syndrome in healthy adults with elevated LDL levels. Br J Nutr 112, 744-752.

53. Sauder KA, McCrea CE, Ulbrecht JS et al. (2014) Pistachio nut consumption modifies systemic hemodynamics, increases heart rate variability, and reduces ambulatory blood pressure in well-controlled type 2 diabetes: a randomized trial. J Am Heart Assoc 3, e000873.

54. Rajaram S, Haddad EH, Mejia A et al. (2009) Walnuts and fatty fish influence different serum lipid fractions in normal 
to mildly hyperlipidemic individuals: a randomized controlled study. Am J Clin Nutr 89, issue 5, 1657S-1663S.

55. Katz DL, Davidhi A, Ma Y et al. (2012) Effects of walnuts on endothelial function in overweight adults with visceral obesity: a randomized, controlled, crossover trial. J Am Coll Nutr 31, 415-423.

56. Medina-Remon A, Tresserra-Rimbau A, Pons A et al. (2015) Effects of total dietary polyphenols on plasma nitric oxide and blood pressure in a high cardiovascular risk cohort. The PREDIMED randomized trial. Nutr Metab Cardiovasc Dis 25, 60-67.

57. Tan SY \& Mattes RD (2013) Appetitive, dietary and health effects of almonds consumed with meals or as snacks: a randomized, controlled trial. Eur J Clin Nutr 67, 1205-1214.

58. Sabaté J (2003) Nut consumption and body weight. Am J Clin Nutr 78, 3 Suppl., 647S-650S. 